\title{
Three-State Switchable Chiral Stationary Phase Based on Helicity Control of an Optically Active Poly(phenylacetylene) Derivative by Using Metal Cations in the Solid State
}

Daisuke Hirose, Asahi Isobe, Emilio Quiñoá, Félix Freire, Katsuhiro Maeda

\section{Accepted Manuscript}

This is the Accepted Manuscript version of a Published Work that appeared in final form in Journal of the American Chemical Society, Copyright (c) 2019 American Chemical Society after peer review and technical edityng by the publisher. To access the final edited and published work see: https://pubs.acs.org/doi/10.1021/jacs.9b03177

\section{How to cite:}

Hirose, D., Isobe, A., Quiñoá, E., Freire, F., \& Maeda, K. (2019). Three-State Switchable Chiral Stationary Phase Based on Helicity Control of an Optically Active Poly(phenylacetylene) Derivative by Using Metal Cations in the Solid State. Journal Of The American Chemical Society, 141(21), 8592-8598. doi: 10.1021/jacs.9b03177

\section{Copyright information:}

(C) 2019 American Chemical Society 


\title{
A Three-State Switchable Chiral Stationary Phase Based on Helicity Control of an Optically Active Poly(phenylacetylene) Derivative by Using Metal Cations in the Solid State
}

\author{
Daisuke Hirose, ${ }^{\dagger, \ddagger}$ Asahi Isobe, ${ }^{\ddagger}$ Emilio Quiñoá, ${ }^{\S}$ Félix Freire ${ }^{\star}$, and Katsuhiro Maeda ${ }^{\star,+\neq}$ \\ ${ }^{\dagger}$ WPI Nano Life Science Institute (WPI-NanoLSI), Kanazawa University, Kakuma-machi, Kanazawa 920-1192, Japan. \\ ${ }^{\ddagger}$ Graduate School of Natural Science and Technology, Kanazawa University, Kakuma-machi, Kanazawa 920-1192, Japan. \\ ${ }^{\S}$ Centro Singular de Investigación en Quimica Biolóxica e Materiais Moleculares (CiQUS), Departamento de Quimica Orgá- \\ nica, Universidade de Santiago de Compostela, E-15782 Santiago de Compostela, Spain \\ KEYWORDS. helical polymer, helicity control, helix inversion, chiral stationary phase, high performance liquid chromatog- \\ raphy, poly(phenylacetylene), switching, chiral recognition ability, metal cation
}

\begin{abstract}
An unprecedented three-state switchable chiral stationary phase (CSP) for high-performance liquid chromatography (HPLC) was developed by using a helical poly(phenylacetylene) bearing a chiral $(R)$ - $\alpha$-methoxyphenylacetic acid residue as the pendant (poly-1). The left- and right-handed helical conformations were induced in poly-1-based CSP upon coordination with a catalytic amount of soluble sodium and cesium tetrakis[3,5-bis(trifluoromethyl)phenyl]borate salts (MBArF), respectively, which are soluble in the HPLC conditions [hexane-2-propanol $(95: 5, \mathrm{v} / \mathrm{v})$ ]. The switch between the two different helical states of poly-1 can be easily done by rinsing the poly-1-based CSP with $\mathrm{MeOH}$ and the subsequent addition of the proper MBArF salt. By using this dynamic helical CSP, we demonstrated how changes on the orientation of secondary structure of a chiral polymer can alter and even invert the elution order of the enantiomers. This study was done without adding chiral additives or changing the mobile phase which could produce changes on the retention times making more difficult to extract the role of the secondary structure during the chiral recognition process.
\end{abstract}

\section{INTRODUCTION}

The separation of enantiomers by high-performance liquid chromatography (HPLC) using a chiral stationary phase (CSP) is one of the most popular and effective methods for both analytical and preparative purposes. ${ }^{1-7}$ In this separation technique, the synthesis of a CSP showing a good chiral recognition ability toward a variety of racemates is essential to attain efficient separation of enantiomers for practical use. Although a significant number of CSPs with excellent resolving abilities have been synthesized, the development of novel CSPs with a good chiral recognition ability remains highly desirable because there exist several racemates that cannot be resolved by using existing commercially available CSPs. Among CSPs developed so far, helical polymer-based CSPs with a helix-sense bias, as represented by single-handed helical poly(triphenylmethyl methacrylate) (PTrMA ${ }^{8-10}$ and polysaccharide derivatives, ${ }^{11-13}$ tend to exhibit good resolving abilities toward a wide range of racemates. $^{14-15}$

Recently, helical polymers capable of controlling the helixsense (right- and left-handed) by external stimuli in the solid state have been attracting great attention due to their potential use as switchable chiral materials. ${ }^{16-17}$ Thus, these materials has been used as switchable asymmetric catalysts and circularly polarized luminescent materials among others. ${ }^{18-25}$ Recently our group reported the first example of elution-order switchable
CSP based on these materials. The CSP is composed of an optically inactive helical polyacetylene carrying 2,2'-biphenol-derived pendants. ${ }^{26}$ Both the macromolecular helicity and axial chirality of the biphenyl pendants were induced in this polymer upon non-covalent interaction with a chiral alcohol even in the solid state as well as in solution and were automatically memorized after complete removal of the chiral alcohol. Based on its unique feature, we have succeeded in switching the elution order of enantiomers by switching the helix-sense of the polymer when this polymer was used as a CSP for HPLC. In this case, a large amount of chiral guests was necessary to control the helixsense. ${ }^{26-28}$ In addition, our group has also developed a foldamer based switchable CSP, which shows reversible coil-to-helix transition in the solid state. ${ }^{29}$ These two macromolecular structures shown different chiral recognition ability depending on their two different conformations (helix and random states) of the foldamer.

Therefore, we believe that multi-state switching function of CSPs will increase the number of resolvable racemates and its versatility for practical use. 


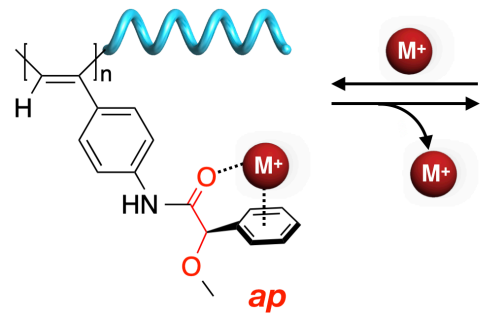

Left-handed helix

$(M$ helix $)$

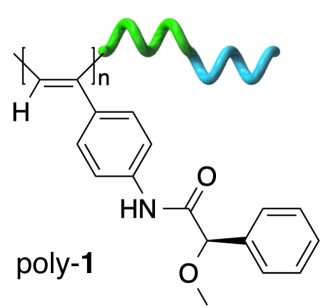

Mixture of

left- and right-handed helices
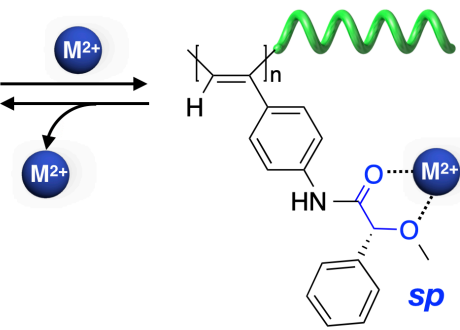

Right-handed helix ( $P$ helix)

Figure 1. Schematic illustration of macromolecular helicity modulation in poly-1 through conformational switching of the MPA pendants using metal cations in solution.

Freire and coworkers previously reported a metal cation-responsive helical poly(phenylacetylene) derivative (poly-1) bearing optically active pendants derived from $(R)$ - $\alpha$-methoxyphenylacetic acid (MPA), whose helix-sense bias was modulated by the addition of a small amount of metal cations in solution (Figure 1) ${ }^{30-32}$ In the absence of metal cations, stereoregular (cis) poly-1 exists as an equal mixture of right-handed $(P)$ and left-handed $(M)$ helical segments in chloroform as confirmed by no CD signal in the absorption region of the polymer backbone. This is because the chiral MPA pendants exist in two different conformations, that is, synperiplanar $(s p)$ and antiperiplanar $(a p)$ conformations depending on the orientation around the $\mathrm{O}=\mathrm{C}-\mathrm{C}-\mathrm{OCH}_{3}$ bond. However, upon the addition of a monovalent cation, such as sodium ion, the MPA pendants take an ap conformation due to cation $-\pi$ interaction, which induces a predominantly $M$ helix in the main-chain. On the other hand, the MPA pendants favor an $s p$ conformation when coordinated with a divalent cation, such as calcium ion, which results in opposite $P$ helix formation in a highly cooperative fashion. $^{30}$ This unique metal cation-triggered conformational change of poly-1 resulting in the adoption of three different folding states $-P_{\text {helix }}, M_{\text {helix }}$ and $P / M_{\text {rac-helix }}$ - stimulated us to apply poly-1 as a CSP for HPLC. In this system, it is possible to obtain from a single chiral pendant group the two opposite helical senses in the polymer without changing the solvent conditions and using achiral metal cations as external stimuli. We anticipated that the $M$ and $P$ or racemic helical states of poly-1 might show largely different chiral recognition abilities toward enantiomers depending on its folding state. However, the helical sense control must work first in the solid state.

\section{RESULTS AND DISCUSSION}

Macromolecular Helicity Control Using Metal Cations in the Solid State. A thin film of poly-1 was prepared first by spincoating its chloroform solution onto a quartz disk in order to investigate whether the helix-sense of poly-1 can be controlled by using metal cations as an external trigger even in the solid state. The as-prepared poly-1 film showed almost no induced circular dichroism (ICD) in the absorption region of the polymer backbone (a in Figure 2A), suggesting that the poly-1 exists as an approximately equal mixture of $P$ and $M$ helical segments in the as-prepared film.

Chiral amplification studies of poly-1 in the solid state by using the metal perchlorate salts described by Freire and coworkers in their work failed due to the poor solubility of the metal salts in the HPLC conditions [hexane-2-propanol eluents].
Thus, it was necessary to look for different metal salts, which are soluble in the HPLC conditions, and where the anion of the salt is inert to the polymer. It was found that sodium salts of triflate (OTf), triflimide $\left(\mathrm{NTf}_{2}\right)$, and tetrakis[3,5-bis(trifluoromethyl)phenyl]borate (BArF) (Figure $2 \mathrm{~B}$ ) meet these requirements and were used as a monovalent cation source.

A

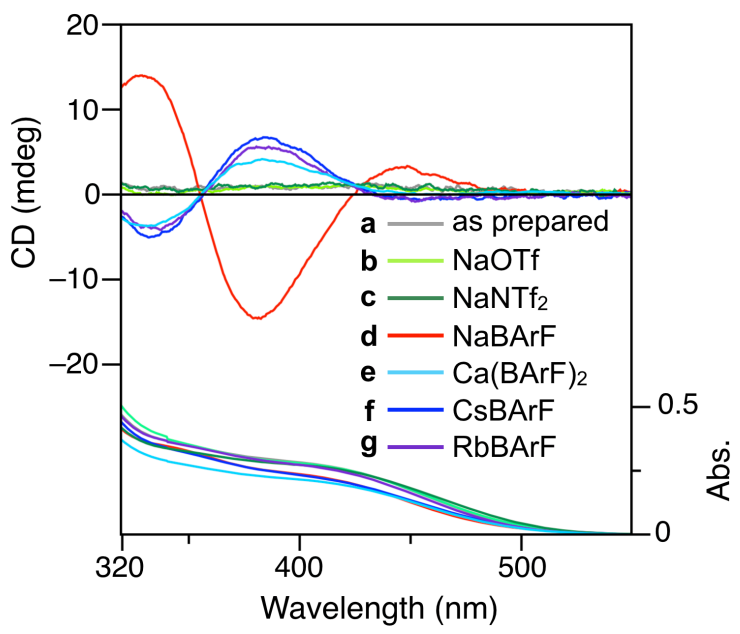

B

$$
\begin{aligned}
& \text { O } \\
& \mathrm{F}_{3} \mathrm{C}^{-\mathrm{S}^{\prime}}
\end{aligned}
$$

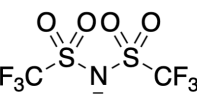

$$
\begin{aligned}
& \text { OTf - } \\
& \mathrm{NTf}_{2}{ }^{-}
\end{aligned}
$$<smiles>FC(F)(F)c1cc([B-](c2cc(C(F)(F)F)cc(C(F)(F)F)c2)(c2cc(C(F)(F)F)cc(C(F)(F)F)c2)c2cc(C(F)(F)F)cc(C(F)(F)F)c2)cc(C(F)(F)F)c1</smiles>

Figure 2. (A) CD and absorption spectra of the poly-1 films before (a) and after soaking in the solutions of sodium salts (NaOTf (b), $\mathrm{NaNTf}_{2}$ (c), and NaBArF (d)), $\mathrm{Ca}(\mathrm{BArF})_{2}$ (e), CsBArF (f), and $\operatorname{RbBArF}(\mathrm{g})$ in hexane-2-propanol $(95: 5, \mathrm{v} / \mathrm{v})$ followed by rinsing with hexane-2-propanol $(95: 5, \mathrm{v} / \mathrm{v})([$ sodium salts $]=[\mathrm{CsBArF}]=$ $\left.[\mathrm{RbBArF}]=2.0 \mathrm{mM},\left[\mathrm{Ca}(\mathrm{BArF})_{2}\right]=0.2 \mathrm{mM}\right) . \mathrm{CD}$ spectra were normalized with respect to the absorbance at $380 \mathrm{~nm}$. (B) Structures of the counter anions.

Poly-1 films were soaked in the different sodium salt solutions $\left\{\left[\mathrm{Na}^{+}\right]=2.0 \mathrm{mM}\right.$ in hexane-2-propanol $\left.(95: 5, \mathrm{v} / \mathrm{v})\right\}$ for 20 minutes followed by rinsing with a large amount of hexane-2propanol $(95: 5, \mathrm{v} / \mathrm{v})$. Next, their CD and absorption spectra 
were then measured. When NaOTf and $\mathrm{NaNTf}_{2}$ were used, no ICD signal was observed above $320 \mathrm{~nm}$ (b and c in Figure 2A), indicating that these counterions are strongly linked to the $\mathrm{Na}^{+}$ ion impeding its coordination to the pendant group (no changes in the IR spectra of poly-1, see Figure S1A and B).

Interestingly, an intense negative Cotton effect was induced around at $380 \mathrm{~nm}$ in the poly-1 film soaked in a solution of $\mathrm{NaBArF}$ (d in Figure 2A). This fact indicates that the expected coordination to the pendant group and the corresponding chiral amplification effect are taking place in the solid state (see Figure S1C). The negative Cotton effect induced around at 380 $\mathrm{nm}$ indicates the formation of a predominantly $M$ helical conformation of the polymer backbone, in accordance to the adoption of a preferred ap conformation in the MPA pendants by coordination with the monovalent sodium cation (Figure 1). ${ }^{30-}$ ${ }^{34}$ (new ref 33-34) The ICD intensity increased with time and when the concentration of NaBArF in hexane-2-propanol $(95: 5, \mathrm{v} / \mathrm{v})$ increases. It was found that the ICD intensity reached a constant value after $20 \mathrm{~min}$ at $[\mathrm{NaBArF}]=2.0 \mathrm{mM}$ (Figure S2). During these studies it was found that the maximum ICD intensity depends on the poly-1 film thickness. The ICD intensity decreases when the film thickness is higher to the one corresponding to $\mathrm{Abs}_{381.5}=0.6$, probably due to the insufficient permeation of a NaBArF solution (Figure S3). Hence, we found conditions to induce an $M$ helix in a poly-1 film by using a NaBArF salt as an external stimulus. This metal salt can deliver the sodium cation as a naked form, allowing its coordination to poly-1 even in the solid state. ${ }^{33-35}$ Therefore, the use of the noncoordinating $\mathrm{BArF}^{-}$as the counter anion is a key for the induction of a preferred-handed helicity in poly- $\mathbf{1}$ in the solid state upon interaction with metal cations.

Next, the induction of the $P$ helix in the poly-1 film was explered. To perform these studies $\mathrm{Ca}(\mathrm{BArF})_{2}$ was as used as a divalent metal cation source taking into account that $\mathrm{Ca}^{2+}$ induced a $P$ helix in poly-1 in solution..$^{30-32}$ As expected, when the film was soaked in a solution of $\mathrm{Ca}(\mathrm{BArF})_{2}\left\{\left[\mathrm{Ca}^{2+}\right]=0.2 \mathrm{mM}\right.$ in hexane-2-propanol $(95: 5, \mathrm{v} / \mathrm{v})\}$, an opposite positive Cotton effect was observed around at $380 \mathrm{~nm}$, indicating that predominantly a $P$ helical conformation was induced in the polymer backbone by coordination with $\mathrm{Ca}^{2+}$ in the solid state (e in Figure 2A). However, the $\mathrm{CD}$ intensity induced by $\mathrm{Ca}(\mathrm{BArF})_{2}$ was much smaller than the one induced by NaBArF ( $d$ in Figure 2A), indicating therefore, the presence of a lower excess of a $P$ helix. This result is explained due to the poor solubility of $\mathrm{Ca}(\mathrm{BArF})_{2}$ in hexane-2-propanol, which made impossible to increase the concentration of $\mathrm{Ca}(\mathrm{BArF})_{2}$ in hexane-2-propanol $(95: 5, \mathrm{v} / \mathrm{v})$ to a value higher than $0.2 \mathrm{mM}$.

To surpass this problem, we decided to use CsBArF and RbBArF as a metal cation source due to their good solubility in hexane-2-propanol (95:5, v/v). These two cations $-\mathrm{Cs}^{+}$and $\mathrm{Rb}^{+}$- were not used in Freire's previous studies due to poor solubility of $\mathrm{CsClO}_{4}$ and $\mathrm{RbClO}_{4}$ in chloroform.

Interestingly, we found that these salts - CsBArF and $\mathrm{RbBArF}$-induce a positive Cotton effect at $380 \mathrm{~nm}$ in poly-1 in the solid state despite the fact that $\mathrm{Cs}^{+}$and $\mathrm{Rb}^{+}$are monovalent cations ( $\mathrm{f}$ and $\mathrm{g}$ in Figure 2A). Moreover, the helix enhancement observed when CsBArF and $\mathrm{RbBArF}$ salts are used as external stimuli is higher than when $\mathrm{Ca}(\mathrm{BArF})$ is used as external metal source. From previous studies we know that monovalent metal ions, such as $\mathrm{Na}^{+}$, can stabilize the $M$ helix in poly-1 by the presence of a cation- $\pi$ interaction. In some cases, depending on the monovalent metal ion and the solvents used to deliver the metal salt, this supramolecular interaction is not produced. ${ }^{32,36}$ In such case, the metal ion chelates the pendant group through the carbonyl and methoxy groups stabilizing the $s p$ conformation and inducing a $P$ helix in poly-1. ${ }^{32,36}$ Therefore, when $\mathrm{Cs}^{+}$and $\mathrm{Rb}^{+}$are used as external stimuli using a mixture of hexane-2-propanol $(95: 5, \mathrm{v} / \mathrm{v})$ as solvent, the cation- $\pi$ interaction is not produced. As a result, a $P$ helix is induced in poly-1 due to the stabilization of the $s p$ conformation at the pendant by coordination with these metal ions (see Figures S1D and S4). ${ }^{37}$ new 33-34

Afterwards, we explored the reversibility of the poly-1 helical sense induction process towards an $M$ or a $P$ helix by using $\mathrm{NaBArF}$ or CsBArF salts, by rinsing the helical polymer metal complex film with a metal trapping solvent. $\mathrm{MeOH}$ was used as a solvent to rinse the poly-1/ $\mathrm{M}^{+}$complex film. It was found that the CD signals above $320 \mathrm{~nm}$ of the polymer film became almost null after $\mathrm{MeOH}$ rinsing. This outcome indicated that the metal salts - NaBArF or CsBArF- were removed from the polymer film. These results were confirmed by infrared studies (Figures S1 and S5).

These chiral amplification studies in the solid state, inducing selectively the $P$ or $M$ helical sense in a racemic helical polymer by using different external stimuli, constitute the foundations to determine how important is the helical sense induced in a chiral polymer - poly-1 - in the enantiomeric resolution of racemic mixtures.

Chiral Recognition Ability as a Switchable CSP for HPLC. In order to investigate the chiral recognition ability of poly-1 as a CSP for HPLC, the poly-1-based CSP was prepared as follows: poly-1 dissolved in chloroform was coated on macroporous silica gel and the obtained packing material was then packed into a stainless-steel column $(25 \times 0.20 \mathrm{~cm}$ (i.d.) $)$ using a conventional high-pressure slurry packing technique. ${ }^{38}$ The column was treated with $\mathrm{MeOH}$ to ensure that poly-1 takes a racemic helical conformation as supported by no CD signal above 320 $\mathrm{nm}$ in the film state. Helicity induction of poly-1 in the column was performed by passing a solution of the metal cation salts through the column. The column was then rinsed with hexane-2-propanol $(95: 5, \mathrm{v} / \mathrm{v})$ to remove the excess metal cations that did not coordinate to the MPA pendants (Figure $3 \mathrm{~A}$ ). The chiral recognition ability of the poly-1-based CSP was evaluated using racemic compounds $\mathbf{2 - 1 0}$ using hexane-2-propanol $(95: 5, \mathrm{v} / \mathrm{v})$ as the eluent (Table 1$)$.

In a first study it was found that the racemic helical poly-1 mixture of $P$ and $M$ helices- obtained either after treatment with $\mathrm{NaOTf}$ and $\mathrm{NaNTf}_{2}$, or even after rinsing with $\mathrm{MeOH}$, could not separate racemates $\mathbf{2}$ and $\mathbf{3}$ (entries 1 and 2 in Table 1 and Table S2).

On the other hand, the NaBArF-treated poly-1, which adopts a predominant $M_{\text {helix }}$ showed a good chiral recognition ability toward racemates 2 and 3 (entries 1 and 2 in Table 1). Figures $3 \mathrm{~B}$ and 3C (top) show the HPLC chromatograms for the resolution of $\mathbf{2}$ and $\mathbf{3}$ after treatment of the column with NaBArF. In the case of racemate 2 , the (+)- and (-)-enantiomers were eluted at different retention times $\left(t_{1}\right.$ and $\left.t_{2}\right)$, showing complete baseline separation. The retention factor $k_{1}\left[=\left(t_{1}-t_{0}\right) / t_{0}\right]$, the separation factor $\alpha\left[=\left(t_{2}-t_{0}\right) /\left(t_{1}-t_{0}\right)\right]$, and the resolution factor 
$R_{\mathrm{S}}\left[=2\left(t_{2}-t_{1}\right) /\left(w_{1}+w_{2}\right)\right]$ were $2.01,2.11$, and 3.48 , respectively, where the hold-up time $\left(t_{0}\right)$ was estimated to be 4.21 min (Figure $3 \mathrm{~B}$ (top) and entry 1 in Table 1).

Moreover, comparison between the results obtained for the two axially racemic poly-1/NaOTf and poly-1/NaNTf 2 complexes, with the ones obtained for poly- $1 / \mathrm{NaBArF}$ complex where a $\mathrm{M}$ helical structure is induced demonstrates that the recognition ability is very influenced by the macromolecular helicity induced in the main chain.
A

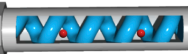

NaBArF-treated poly-1

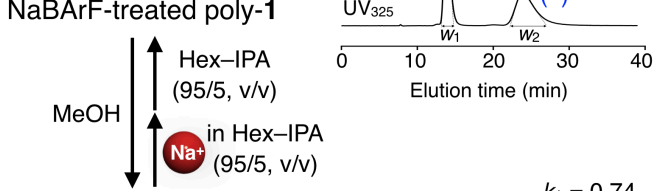

B racemate 2
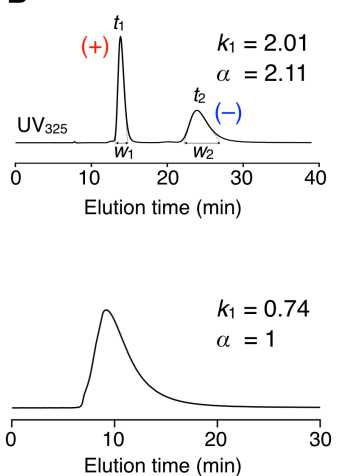

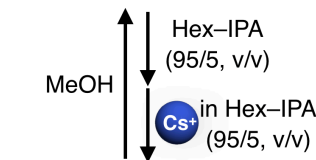

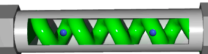

CsBArF-treated poly-1

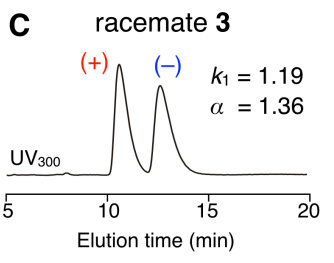

D racemate 5

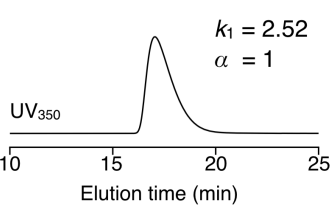

E racemate $\mathbf{9}$
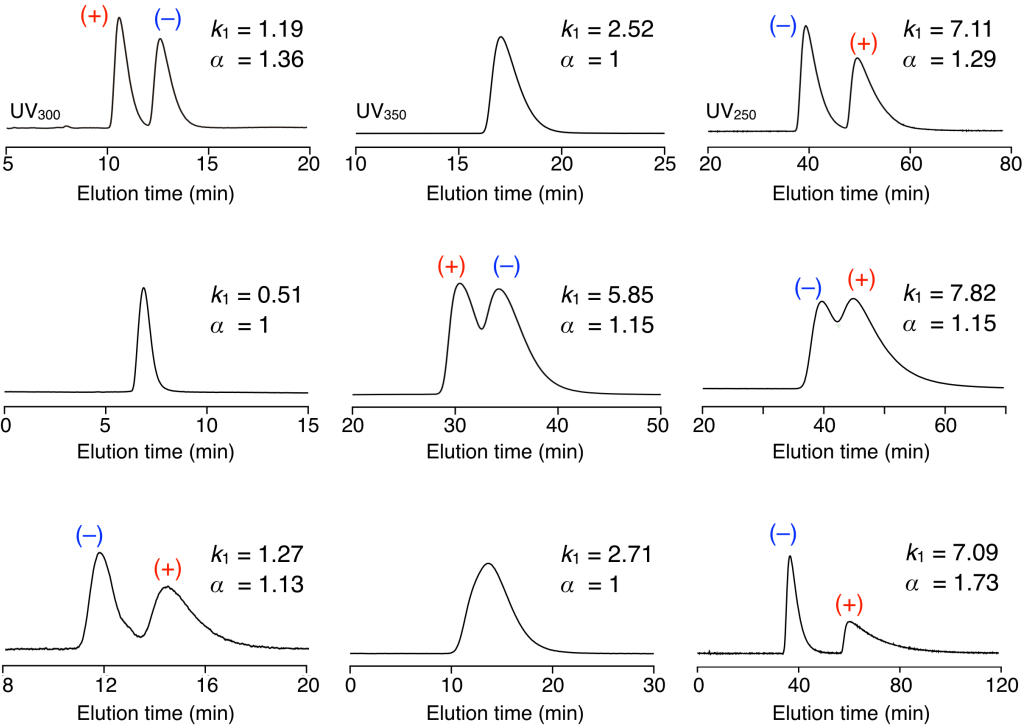

Figure 3. (A) Schematic illustration of helicity induction of poly-1-based CSP in the column. (B-E) HPLC chromatograms for the resolution of racemates 2 (B), 3 (C), 5 (D), and 9 (E) on the NaBArF- (top), MeOH- (middle), and CsBArF-treated (bottom) poly-1s. Eluent: hexane2-propanol $(95: 5, \mathrm{v} / \mathrm{v})$.

Table 1. Resolution Results of Racemates on NaBArF-, MeOH-, and CsBArF-treated Poly-1 ${ }^{a}$

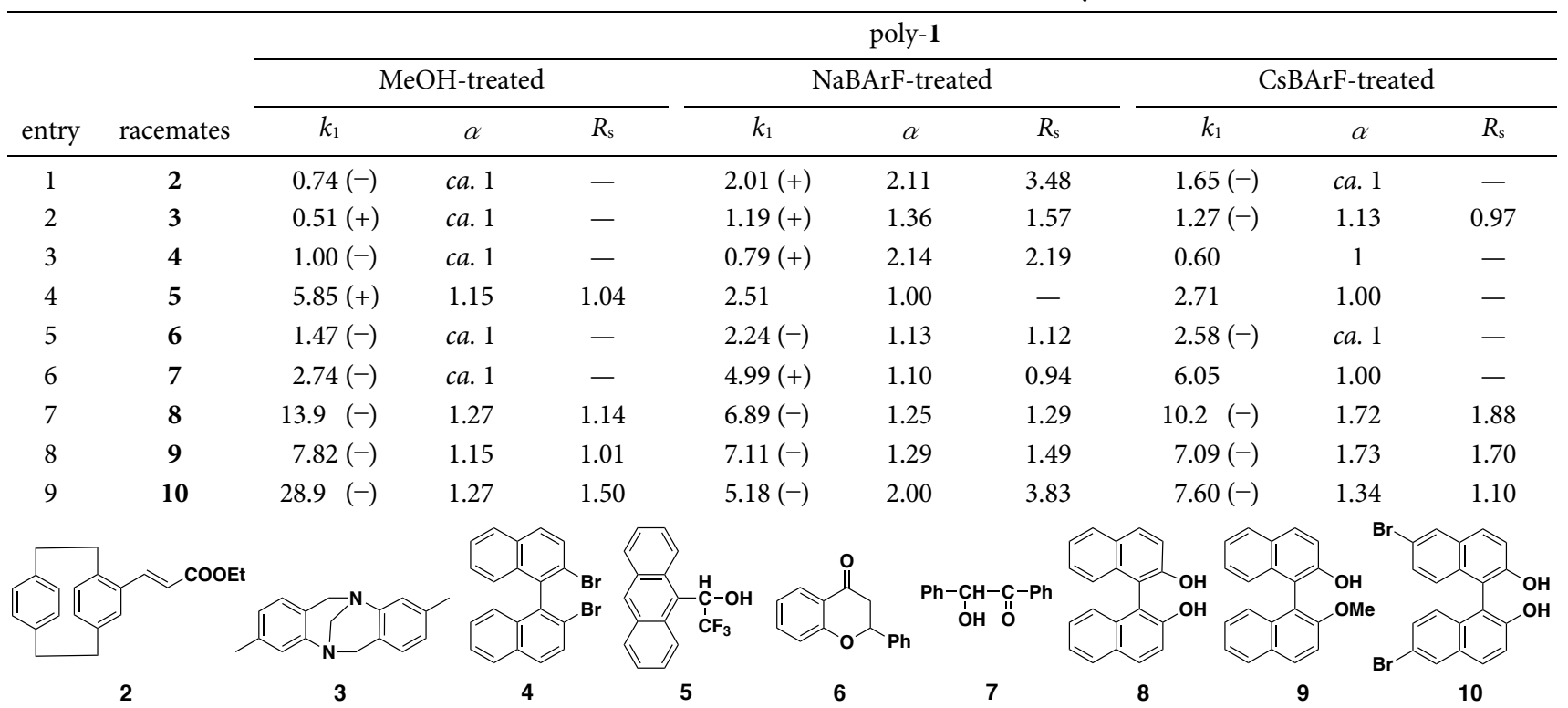

${ }^{a}$ Conditions: column, $25 \times 0.20 \mathrm{~cm}$ (i.d.); flow rate: $0.2 \mathrm{~mL} \cdot \mathrm{min}^{-1}$; eluent, hexane-2-propanol $(95: 5, \mathrm{v} / \mathrm{v})$; temperature, $0{ }^{\circ} \mathrm{C}(\mathrm{NaBArF}-$ and CsBArF-treated) and ca. $25^{\circ} \mathrm{C}$ (MeOH-treated). The signs in parentheses represent the Cotton effect sign at $254 \mathrm{~nm}$ of the first-eluted enantiomers.

To confirm the importance of the macromolecular helicity on the chiral recognition for racemate 2 , the cis stereoregular poly1 was converted into the stereoirregular polymer ( $g$-poly-1) by grinding poly-1 as reported in previous works. ${ }^{39-40}$ The $g$-poly-1 film prepared on a quartz disk showed no ICD in the polymer backbone even after treatment with a solution of NaBArF, indicating no helical sense induction in $g$-poly-1 upon coordination with a sodium cation in the solid state (Figure S6). Moreover, 
the $g$-poly-1-based CSP showed almost no change in the chiral recognition ability before and after treatment with $\mathrm{NaBArF}$, being almost the same as the one observed for poly-1 after treatment with $\mathrm{MeOH}$ that generates the racemic helical polymer (Table S3). Hence, these results clearly demonstrate that the change in the helical conformation of poly-1, from a racemic helical polymer towards an $M$ helix, play a key role in the significant change of the chiral recognition ability of the NaBArFtreated poly-1.

The $\alpha$ value on the NaBArF-treated poly-1 reached an almost constant value after flowing a $2.0 \mathrm{mM} \mathrm{NaBArF}$ solution in hexane-2-propanol $(95: 5, \mathrm{v} / \mathrm{v})$ for $4 \mathrm{~h}$ at a flow rate of $0.2 \mathrm{~mL} \cdot \mathrm{min}^{-}$ ${ }^{1}$ (Table S4). The total amount of NaBArF used for the helix induction of poly-1 coated on silica gel was estimated to be in a $[\mathrm{NaBArF}] /$ poly-1 (m.r.u.) $\mathrm{ratio}=2.0 / 5.0(\mathrm{~mol} / \mathrm{mol})$ of the amount of the poly-1 which was determined by TG analysis. This result indicates that the poly-1-based CSP needs only catalytic amounts of $\mathrm{NaBArF}$ to induce a single-handed helix into the polymer and therefore to complete the switching of the chiral recognition ability. In addition, NMR studies were done to determine the amounts of metal cations coordinated to the poly-1-based CSP after treatment with NaBArF. To perform these NMR studies, the poly-1/NaBArf-based CSP complex was rinsed with MEOD, extracting the metal salt from the CSP to the solution phase. By using this approach the ratio of the coordinating amount of NaBArF to poly-1 $\left\{\left[\mathrm{Na}^{+}\right] /[\right.$poly-1] (m.r.u.) $\}$ was estimated to be in a $1 / 10(\mathrm{~mol} / \mathrm{mol})$ ratio. These results clearly confirm that the helical sense switch of poly-1 is produced in the solid state by using a catalytic amount of metal cations.

Next, similar studies were done for the CsBArF-treated poly1. In this case, a $P$ helix is induced in the poly-1/Cs ${ }^{+}$-based CSP and it was observed that the chiral recognition ability for racemate 2 decreases (entry 1 in Table 1, Figure 3B (bottom)). An interesting phenomenon occurs during the study of the chiral recognition of racemate 3 . Now, the baseline separation was achieved by using both $\mathrm{NaBArF}$ and CsBArF-treated poly-1based CSPs, although opposite elution order of the enantiomers was found (entry 2 in Table 1, Figure 3C (top and bottom)). ${ }^{26}$ Therefore, elution order switching was achieved by interchanging the main-chain helicity of a chiral polymer in the solid state by resorting to achiral metal cations. These results clearly confirm that the enantioseparation of racemate 3 is directly related to the macromolecular helicity adopted by poly- $\mathbf{1}$.

TGA and NMR studies for the CsBArF-treated poly-1-based CSP, analogous to those described above for NaBArF-treated poly-1-based CSP, indicate again that poly-1-based CSP needs only catalytic amounts of CsBArF to induce a single handed helix into the polymer and therefore to complete the switching of the chiral recognition ability.

Later, the resolution results of racemates 4-10 on poly-1 in three different states as the CSP (NaBArF-, CsBArF-, and $\mathrm{MeOH}$-treated poly-1) were compared (see Table 1). In the case of racemates 4,6 , and 7 , the $M$ helix induced by the NaBArFtreated poly-1-based CSP is the only one that shows chiral recognition ability. This fact also corroborates the importance of the macromolecular helicity adopted by a chiral polymer in its chiral recognition ability. Racemates $\mathbf{8 - 1 0}$ were resolved on the three different states of the chiral poly-1 $-M, P$, and racemic macromolecular helicity-, but it is the $P$ helix (for $\mathbf{8}$ and 9) or the $M$ helix (for 10) the one that provides the best results (Figure 3E). It is also noteworthy that the $\mathrm{MeOH}$-treated poly1 resolved racemate $\mathbf{5}$, which were not resolved by the other states (Figure 3D). Therefore, just by treating the CSP with catalytic amount of achiral metal cations or $\mathrm{MeOH}$, we can tune the state of the CSP to show the best chiral recognition ability toward the target enantiomers.

These chiral recognition abilities in the induced states were maintained over 4 days under the flow condition in continuous use (Figure S7). Furthermore, the NaBArF-treated poly-1 CSP showed no significant change in the a value of racemate $\mathbf{2}$ after standing at $-20^{\circ} \mathrm{C}$ for 13 days (Table S5).

Finally, cycles of activation/deactivation of macromolecular helicity in the poly-1-based CSP carried out by combinations of metal salts and $\mathrm{MeOH}$ rinse $-\mathrm{CsBArF} / \mathrm{MeOH} / \mathrm{NaB}-$ $\mathrm{ArF} / \mathrm{MeOH} / \mathrm{NaBArF} / \mathrm{MeOH}$ - were done to determine the stability of the CSP. These studies showed that the chiral recognition ability of poly-1-based CSP was stable through the different repeating switches of the macromolecular helicity (Figure 4).

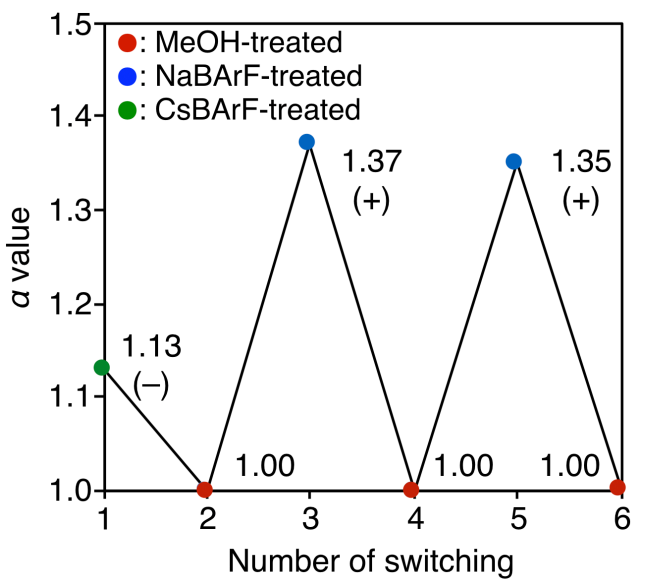

Figure 4. Plots of the $\alpha$ values for racemate 3 on poly-1 at each state. Eluent: hexane-2-propanol (95:5, v/v).

\section{Conclusions}

In summary, we have demonstrated the key role of the macromolecular helicity ( $P$ or $M$ helix) in the chiral recognition ability of a chiral stationary phase. To perform these studies, it was necessary to prepare a chiral stationary phase coated with a chiral helical polymer that can adopt selectively the two possible helical senses without changing the environmental conditions, such as solvent polarity. This study was possible by using poly$\mathbf{1}$ as stationary phase. This polymer behaves as axially racemic in hexane-2-propanol (95:5, v/v), although a specific $M$ or $P$ helical sense can be induced in this poly-1-based CSP by the addition of a catalytic amount of $\mathrm{NaBArF}$ or CsBArF, respectively. This macromolecular helicity induction is reversible, and a single chiral stationary phase with racemic helical structure can be transformed into two chiral stationary phases with either a $P$ or $M$ helical structure by rinsing it with $\mathrm{MeOH}$ and adding the appropriate BArF salt of metal cations. Through this study we found that it is possible to invert the elution order of the two enantiomers of racemate 3 by switching the macromolecular helicity of a single chiral polymer through the use of an 
appropriate achiral external stimulus. To the best of our knowledge, this is the first example of CSPs for HPLC capable of switching reversibly its chiral recognition ability among three different states by using external achiral stimuli. It was also demonstrated how the helical structure adopted can invert the retention time of the two enantiomers of a chiral molecule, or can separate a racemic mixture either in the $P$ or $M$ form but not in the opposite. Further research to develop a more efficient switchable CSP with higher chiral recognition ability toward many racemates is currently in progress in our laboratories.

\section{ASSOCIATED CONTENT}

\section{Supporting Information}

The Supporting Information is available free of charge on the ACS Publications website at DOI: XXXXXXXXXX.

Materials and methods and supporting data (PDF)

\section{AUTHOR INFORMATION}

\section{Corresponding Author}

${ }^{\star}$ K. Maeda. E-mail: maeda@se.kanazawa-u.ac.jp.

${ }^{*}$ F. Freire. E-mail: felix.freire@usc.es

\section{ACKNOWLEDGMENT}

Authors thank Prof. Hasegawa (Kanazawa University) for his help in the analysis of BArF salts. This work was supported by JSPS KAKENHI Grant No. 16H04154 (Grants-in-Aid for Scientific Research (B)) and 17H05361 (Coordination Asymmetry) (K.M.).

\section{REFERENCE}

1. Pirkle, W. H.; Pochapsky, T. C., Considerations of Chiral Recognition Relevant to the Liquid Chromatography Separation of Enantiomers. Chem. Rev. 1989, 89, 347-362.

2. Maier, N. M.; Franco, P.; Lindner, W., Separation of Enantiomers: Needs, Challenges, Perspectives. J. Chromatogr. A 2001, 906, 3-33.

3. Francotte, E. R., Enantioselective Chromatography as a Powerful Alternative for the Preparation of Drug Enantiomers. J. Chromatogr. A 2001, 906, 379-397.

4. Andersson, S.; Allenmark, S. G., Preparative Chiral Chromatographic Resolution of Enantiomers in Drug Discovery. Journal of Biochemical and Biophysical Methods 2002, 54, 11-23.

5. Liu, Y.; Lantz, A. W.; Armstrong, D. W., High Efficiency Liquid and Super-/Subcritical Fluid-Based Enantiomeric Separations: An Overview. J. Liq. Chromatogr. Relat. Technol. 2004, 27, 1121-1178. 6. Thompson, R., A Practical Guide to HPLC Enantioseparations for Pharmaceutical Compounds. J. Liq. Chromatogr. Relat. Technol. 2005, 28, 1215-1231.

7. Okamoto, Y.; Ikai, T., Chiral HPLC for Efficient Resolution of Enantiomers. Chem. Soc. Rev. 2008, 37, 2593-2608.

8. Yuki, H.; Okamoto, Y.; Okamoto, I., Resolution of Racemic Compounds by Optically Active Poly(triphenylmethyl methacrylate). J. Am. Chem. Soc. 1980, 102, 6356-6358.

9. Okamoto, Y.; Honda, S.; Okamoto, I.; Yuki, H.; Murata, S.; Noyori, R.; Takaya, H., Novel Packing Material for Optical Resolution: (+)-Poly(triphenylmethyl methacrylate) Coated on Macroporous Silica Gel. J. Am. Chem. Soc. 1981, 103, 6971-6973.

10. Nakano, T., Optically Active Synthetic Polymers as Chiral Stationary Phases in HPLC. J. Chromatogr. A 2001, 906, 205-225.

11. Okamoto, Y.; Yashima, E., Polysaccharide Derivatives for Chromatographic Separation of Enantiomers. Angew. Chem. Int. Ed. 1998, 37, 1020-1043.
12. Yashima, E., Polysaccharide-Based Chiral Stationary Phases for High-Performance Liquid Chromatographic Enantioseparation. J. Chromatogr. A 2001, 906, 105-125.

13. Ikai, T.; Okamoto, Y., Structure Control of Polysaccharide Derivatives for Efficient Separation of Enantiomers by Chromatography. Chem. Rev. 2009, 109, 6077-6101.

14. Yamamoto, C.; Okamoto, Y., Optically Active Polymers for Chiral Separation. Bulletin of the Chemical Society of Japan 2004, 77, 227-257.

15. Shen, J.; Okamoto, Y., Efficient Separation of Enantiomers Using Stereoregular Chiral Polymers. Chem. Rev. 2016, 116, 10941138.

16. Yashima, E.; Maeda, K.; Iida, H.; Furusho, Y.; Nagai, K., Helical polymers: Synthesis, structures, and functions. Chem. Rev. 2009, 109, 6102-6211.

17. Yashima, E.; Ousaka, N.; Taura, D.; Shimomura, K.; Ikai, T.; Maeda, K., Supramolecular Helical Systems: Helical Assemblies of Small Molecules, Foldamers, and Polymers with Chiral Amplification and Their Functions. Chem. Rev. 2016, 116, 13752-13990.

18. Cheon, K. S.; Selinger, J. V.; Green, M. M., Designing a Helical Polymer that Reverses its Handedness at a Selected, Continuously Variable, Temperature. Angew. Chem. Int. Ed. 2000, 39, 1482-1485.

19. Ohira, A.; Kunitake, M.; Fujiki, M.; Naito, M.; Saxena, A., Helical Shape Memory of Screw-Sense Switchable Polysilanes in Cast Films. Chem. Mater. 2004, 16, 3919-3923.

20. Fukushima, T.; Takachi, K.; Tsuchihara, K., Optically Active Poly(phenylacetylene) Film: Chirality Inversion Induced by Solvent Vapor and Heating. Macromolecules 2008, 41, 6599-6601.

21. Pijper, D.; Jongejan, M. G. M.; Meetsma, A.; Feringa, B. L., Light-Controlled Supramolecular Helicity of a Liquid Crystalline Phase Using a Helical Polymer Functionalized with a Single Chiroptical Molecular Switch. J. Am. Chem. Soc. 2008, 130, 4541-4552.

22. Yamamoto, T.; Yamada, T.; Nagata, Y.; Suginome, M., HighMolecular-Weight Polyquinoxaline-Based Helically Chiral Phosphine (PQXphos) as Chirality-Switchable, Reusable, and Highly Enantioselective Monodentate Ligand in Catalytic Asymmetric Hydrosilylation of Styrenes. J. Am. Chem. Soc. 2010, 132, 7899-7901.

23. Wang, Y.; Sakamoto, T.; Nakano, T., Molecular Chirality Induction to an Achiral $\pi$-Conjugated Polymer by Circularly Polarized Light. Chem. Commun. 2012, 48, 1871-1873.

24. Nagata, Y.; Nishikawa, T.; Suginome, M., ChiralitySwitchable Circularly Polarized Luminescence in Solution Based on the Solvent-Dependent Helix Inversion of Poly(quinoxaline-2,3-diyl)s. Chem. Commun. 2014, 50, 9951-9953.

25. Nishikawa, T.; Nagata, Y.; Suginome, M., Poly(quinoxaline2,3-diyl) as a Multifunctional Chiral Scaffold for Circularly Polarized Luminescent Materials: Color Tuning, Energy Transfer, and Switching of the CPL Handedness. ACS Macro Lett. 2017, 6, 431-435.

26. Shimomura, K.; Ikai, T.; Kanoh, S.; Yashima, E.; Maeda, K., Switchable Enantioseparation Based on Macromolecular Memory of a Helical Polyacetylene in the Solid State. Nat. Chem. 2014, 6, 429-434.

27. Ishidate, R.; Shimomura, K.; Ikai, T.; Kanoh, S.; Maeda, K., Macromolecular Helicity Induction and Memory in a Poly(biphenylylacetylene) Bearing an Ester Group and Its Application to a Chiral Stationary Phase for High-performance Liquid Chromatography. Chem. Lett. 2015, 44, 946-948.

28. Ishidate, R.; Ikai, T.; Kanoh, S.; Yashima, E.; Maeda, K., Chromatographic Enantioseparation by Poly(biphenylylacetylene) Derivatives with Memory of both Axial Chirality and Macromolecular Helicity. Chirality 2017, 29, 120-129.

29. Ikai, T.; Awata, S.; Kudo, T.; Ishidate, R.; Maeda, K.; Kanoh, S., Chiral Stationary Phases Consisting of $\pi$-conjugated Polymers Bearing Glucose-Linked Biphenyl Units: Reversible Switching of Resolution Abilities Based on a Coil-to-Helix Transition. Polym. Chem. 2017, 8, 4190-4198.

30. Freire, F.; Seco, J. M.; Quinoa, E.; Riguera, R., Chiral Amplification and Helical-Sense Tuning by Mono- and Divalent 
Metals on Dynamic Helical Polymers. Angew. Chem. Int. Ed. 2011, 50, 11692-11696.

31. Freire, F.; Seco, J. M.; Quinoa, E.; Riguera, R., Nanospheres with Tunable Size and Chirality from Helical Polymer-Metal Complexes. J. Am. Chem. Soc. 2012, 134, 19374-19383.

32. Arias, S.; Freire, F.; Quinoa, E.; Riguera, R., The Leading Role of Cation- $\pi$ Interactions in Polymer Chemistry: the Control of the Helical Sense in Solution. Polym. Chem. 2015, 6, 4725-4733.

33. Engesser, T. A.; Lichtenthaler, M. R.; Schleep, M.; Krossing, I., Reactive p-Block Cations Stabilized by Weakly Coordinating Anions. Chem. Soc. Rev. 2016, 45, 789-899.

34. Kitazawa, Y.; Takita, R.; Yoshida, K.; Muranaka, A.; Matsubara, S.; Uchiyama, M., "Naked" Lithium Cation: Strongly Activated Metal Cations Facilitated by Carborane Anions. J. Org. Chem. 2017, 82, 1931-1935.

35. $\quad$ Chang, Y. H.; Lee, Y. J.; Lai, C. C.; Liu, Y. H.; Peng, S. M.; Chiu, S. H., Synthesis of Oxygen-Free [2]Rotaxanes: Recognition of Diarylguanidinium Ions by Tetraazacyclophanes. Org. Lett. 2018, 20, 2416-2419.

36. Arias, S.; Bergueiro, J.; Freire, F.; Quinoa, E.; Riguera, R., Chiral Nanostructures from Helical Copolymer-Metal Complexes: Tunable Cation $-\pi$ Interactions and Sergeants and Soldiers Effect. Small 2016, 12, 238-244

37. When $\mathrm{Cs}^{+}$and $\mathrm{Rb}^{+}$are used as external stimuli in chloroform-hexane $(6 / 5, \mathrm{v} / \mathrm{v})$, poly-1 also showed a positive ICD at 380 $\mathrm{nm}$, suggesting the formation of a $P$ helix due to the stabilization of the $s p$ conformation at the pendant by coordination with these metal ions. 38. Okamoto, Y.; Kawashima, M.; Hatada, K., Chromatographic Resolution: XI. Controlled Chiral Recognition of Cellulose Triphenylcarbamate Derivatives Supported on Silica Gel. J. Chromatogr. A 1986, 363, 173-186.

39. Tabata, M.; Tanaka, Y.; Sadahiro, Y.; Sone, T.; Yokota, K.; Miura, I., Pressure-Induced Cis to Trans Isomerization of Aromatic Polyacetylenes. 2. Poly((o-ethoxyphenyl)acetylene) Stereoregularly Polymerized Using a Rh Complex Catalyst. Macromolecules 1997, 30, 5200-5204.

40. Tang, Z. L.; Iida, H.; Hu, H. Y.; Yashima, E., Remarkable Enhancement of the Enantioselectivity of an Organocatalyzed Asymmetric Henry Reaction Assisted by Helical Poly(phenylacetylene)s Bearing Cinchona Alkaloid Pendants via an Amide Linkage. ACS Macro Lett. 2012, 1, 261-265.

33) Fernández, B.; Rodríguez, R.; Rizzo, A.; Quiñoá, E.; Riguera, R.; Freire, F. Predicting the Helical Sense of Poly(phenylacetylene)s from their Electron Circular Dichroism Spectra. Angew. Chem., Int. Ed. 2018, 57, 3666-3670.

34) Fernández, B.; Rodríguez, R.; Rizzo, A.; Quiñoá, E.; Riguera, R.; Freire, F. Decoding the ECD spectra of Poly(phenylacetylene)s: Structural significance.ACS Omega 2019, 4, 5233-5240. 
TOC Graphic :

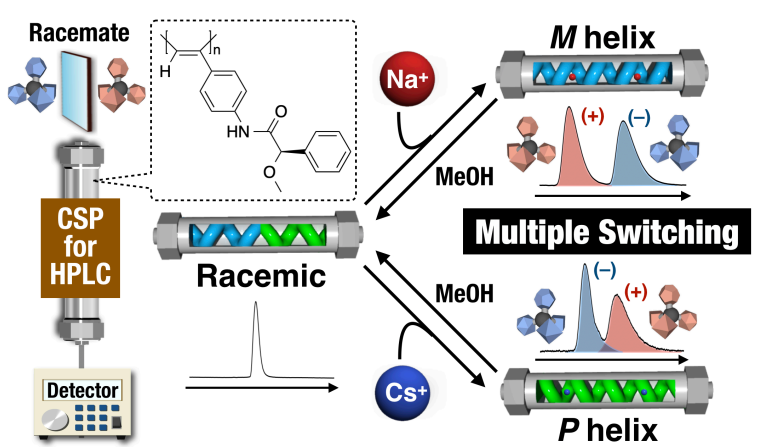

